\title{
Transpersonal Art: A Conversation with Artist Judy Schavrien
}

\author{
Dorit Netzer ${ }^{1}$ \\ Hofstra University \\ dorit.netzer@hofstra.edu \\ Judy Schavrien \\ Walnut Creek, CA \\ judynow@comcast.net
}

\begin{abstract}
This article presents an excerpt from an interview with Judy Schavrien, a transpersonal psychology scholar, poet, and artist. In the course of this dialogue, Schavrien uncovers the philosophical and psychosocial underpinnings for the artworks included in her books Alice at the Rabbithole Café and Everything Voluptuous: The Love Songs 1970-2014. The collegial conversation, unstructured in advance yet guided by the art it explores, inquires into the following: the role of the transpersonal artist-scholar; the meaning Schavrien attributes to her subject matter; the environments and people that act as catalysts; the relevance of her choice of media and process; and, finally, whether the aims in her art and research converge. It becomes clear that, for Schavrien, it is not enough for artists to be mere custodians of their culture. Their role, in her view, is to challenge conventions, cry out, provoke thought, engage multiple ways of knowing, and offer alternatives that push society forward. Her research intends the same. Both Schavrien and the interviewer perceive a participatory element in her art, her research, and the approach taken in this article that explores them.
\end{abstract}

Keywords: transpersonal psychology, participatory research, political art, computer art, feminist art, artinformed scholarship, portrait, social activism

\footnotetext{
${ }^{1}$ Biographical statement: Dorit Netzer, PhD, ATR-BC, LCAT is an art therapist in private practice. She works with children, adults, couples and families, incorporating creative expression with a focus on healing and spiritual development. In addition to her clinical practice, Dorit is an adjunct research faculty at Sofia University, CA (Formerly the Institute of Transpersonal Psychology), and an assistant adjunct professor of Creative Art Therapy at Hofstra University, NY. She is a qualitative researcher, who focuses on the role of imagery and creative expression in human development and transformative learning. https://hofstra.academia.edu/DoritNetzer

Judy Schavrien, PhD, MFT is an artist and psychotherapist in the San Francisco Bay Area. She has received 18 awards for work in the arts and theory, a nomination for Oakland, California artist of the year, and has been featured in a cover article for the international feminist journal On The Issues. Her books are Shot Awake: A Painter's Memoir, Alice at the Rabbithole Cafe, and Everything Voluptuous: The Love Songs 1970-2014. Her art and writing are at Amazon, Kindle, and www.jesart.net
} 


\section{Introduction}

In the autumn of 2014, I met with Judy Schavrien, a transpersonal psychology scholar, poet, and artist, for a conversation about her latest books. One of them is Alice at the Rabbithole Café-a small volume of drawings and paintings, all created on the iPad. The other is Everything Voluptuous: The Love Songs 1970-2014, a collection of poems and art. What brought the two of us together for this interview? I had been her doctoral student at the Institute of Transpersonal Psychology (ITP). Eventually we became colleagues on the faculty. I initiated the interview because her iPad drawings especially, with their witty explorations of café life, piqued my curiosity. Why had she chosen this new medium, new, at least, to people of her generation and even mine? Was I right to see frequent reference to the long tradition of prints alongside glances at New Yorker cartooning? The two of us shared both a passion and a training as not only researchers but also artists. We also both gave our special devotion, as psychotherapists, researchers, and teachers, to the field of transpersonal psychology. This conversation promised to be a rich one. It would, I imagined, explore convergences and perhaps begin to answer such questions as: What is transpersonal about Schavrien's art-and, it may be inferred-about art in general? What is transpersonal about her research? Do they parallel or enhance each other?

We sat outdoors, on the porch of the old building that housed, during the 1980s, the graduate program of the Institute of Transpersonal Psychology. Our voices carried above the street sounds of a California Bay Area suburb.

Over the past 10 years I had seen many of Schavrien's original artworks. My background in art psychotherapy and subsequent studies of transpersonal psychology informed my appreciation and understanding of her art in the context of her teaching. Transpersonal psychology regards body, mind, and spirit as equally important. It takes a holistic view of the individual in a global context: interconnected and interdependent. Transpersonal psychologists and researchers draw knowledge from a broad range of disciplines in the natural and social sciences, the humanities, and the arts, resulting in a broad range of academic investigations as well as diverse therapeutic practices, which include ancient wisdom traditions and advanced scientific discoveries. Normalizing the paranormal and embracing exceptional experiences (e.g., near death, spiritual emergence, clairvoyance) as integral to human development have led this field to value multiple ways of knowing, including intuition, imagination, and body knowing (e.g., Anderson \& Braud, 2011; Caplan, Hartelius, \& Rardin, 2003; Friedman \& Hartelius, 2013).

A definition of transpersonal well suited to this interview is one offered by Michael Daniels (2005). Similar to Schavrien, whether with her sociocultural basis for teaching what may be briefly, and inadequately, described as spiritual psychology, or her largeformat pieces that echo street art, Daniels takes a field like transpersonal psychology and broadens it beyond the researching and often parallel pursuit of private sacred 
experiences to a more accurate description, one that comprehends a very broad range of psychological phenomena and research approaches. Moreover, in this view of the transpersonal, research and practice go hand in hand. The transpersonal psychologist's commitment, in research or clinical work, to personal and social transformation entails transformation through and beyond the personal (Daniels, 2005).

Schavrien trained as a transdisciplinary scholar with various world-class intellectuals: Joshua Taylor, director of the American wing of the Smithsonian; Harold Rosenberg, art critic for The New Yorker; Bruno Bettelheim and Eugene Gendlin (first president of the American Psychological Association, Clinical Division); Saul Bellow, Nobel Laureate novelist; and Hannah Arendt, political philosopher. David Grene taught her about poetry and the image; he was an esteemed translator of the Greek tragedies-which provided a depth psychology (the psychology Freud took from Oedipus Rex) and images of personal and political healing (Oedipus at Colonus) that occupied Schavrien's research (e.g., Schavrien, 2013) for many years. Several of her teachers broke conventions in their youth and eventually set the new ones. Rosenberg, Bellow, Grene, and Arendt, thinkers who were transdisciplinary, or joined thought with image, were black sheep, embraced only belatedly by the academic establishment.

Soon after completing her doctorate, Schavrien trained as a humanistic psychotherapist. Abraham Maslow $(1962,1971)$ widened humanistic theory when the drug/mysticism/meditation expansions of the states-of-consciousness mind map took place experientially. At that time, Maslow cooperated with others to found transpersonal psychology. Likewise Schavrien's own horizons widened from their humanistic personcentered base. She studied for many years with a Tibetan Buddhist Dzogchen lama (Dzogchen is the Zen of Tibetan Buddhism, the lightning-path) named Sogyal Rinpoche, "the laughing lama." With the years, Schavrien focused more on her art. She said:

This got seeded when I had just obtained my doctorate and was spending a year off in Amsterdam, freed now to progress as a poet. In the meantime, Van Gogh and Rembrandt spoke to me from the museums there, compelled me, really. A seed was planted. Though I remained a psychotherapist, scholar, and poet for some decades, the poet part gradually yielded to visual artist. Why? As a Babyboomer I had the Romantic view of truth; it had to be dug out from the debris, made visible despite the whitewash. There was a parallel between the defensive ploys and cover-ups during this era of Vietnam, civil rights, and the women's movement and the obstacles to truth-telling in my own personality. I was just too glib verbally; I could more easily lie. The visual, the drafting, was not my natural talent. Maybe the truth would come through better if I spoke in that language. Furthermore, I thought, if one could show the soul and the embracing 
surround, as did Rembrandt, as did Van Gogh, that would be best. (Schavrien, personal communication, March 9, 2016)

As a transpersonal psychology professor in an international, low-residence program at ITP, Schavrien constructed a sequence of courses that introduced advanced doctoral students to global psychologies. The degree was "psychologist" but would eschew a narrow focus on unquestioned Western premises, such as narrow definitions of human experiences; the exclusive merit of, so called, objective scientific investigation in the social sciences; and prevailing, dominant cultural norms. As a transpersonal researcher and practitioner, in a field that often emphasized private psychospiritual experiences, whether of the mystic or the transpersonal meditator, her curriculum instead gave students grounding in sociocultural context, differing philosophical premises of sacred theologies around the world, and, in the course of intensive seminars and online conversations, the role of the arts. Taking the same approach as she has taken with her artwork - questioning conventions and experimenting with media and her subject matter-Schavrien trained her students to identify multiple ways of knowing, through the felt senses of the body as well as thinking by way of images and not by way of concepts alone.

At the same time, transpersonal concepts have been palpably evoked in Schavrien's portraits, manifesting what Maslow (1962) called creative freedom:

[the capacity to] see the fresh, the raw, the concrete, the ideographic, as well as the generic, the abstract, the rubricized, the categorized and the classified ... . [and consequently the ability to] live far more in the real world of nature than in the verbalized world of concepts, abstractions, expectations, beliefs and stereotypes that most people confuse with the real world. (Maslow, 1962, p. 129)

Her iPad art includes quick, impromptu cartoon-like sketches (e.g., Figure 1), and carefully rendered drawings (e.g., Figure 2 ). ${ }^{2}$ Although as contemporary as can be, Schavrien's use of the digital medium echoes traditional prints: lithos, etchings, and woodcuts. Like her large-scale pastels, the café digital sketches explore human expression. The expression may be that of an individual or may be one altered by social interaction. A false floor underneath drops away, revealing the larger societal dynamic, suggesting social concerns. There is, for instance, the impact of the digital age on human relationships (an interesting exploration on Schavrien's part given the digital medium she employs).

\footnotetext{
${ }^{2}$ Figures 1, 2, and 4 were first published in Alice at the rabbithole café: iPad art by JES Schavrien (CreateSpace Independent Publishing, 2014). Figure 3 was first published in Everything voluptuous: The love songs 1970-2014 (Blue Tile Press, 2014). Figure 5 is unpublished, in the artist's collection.
} 


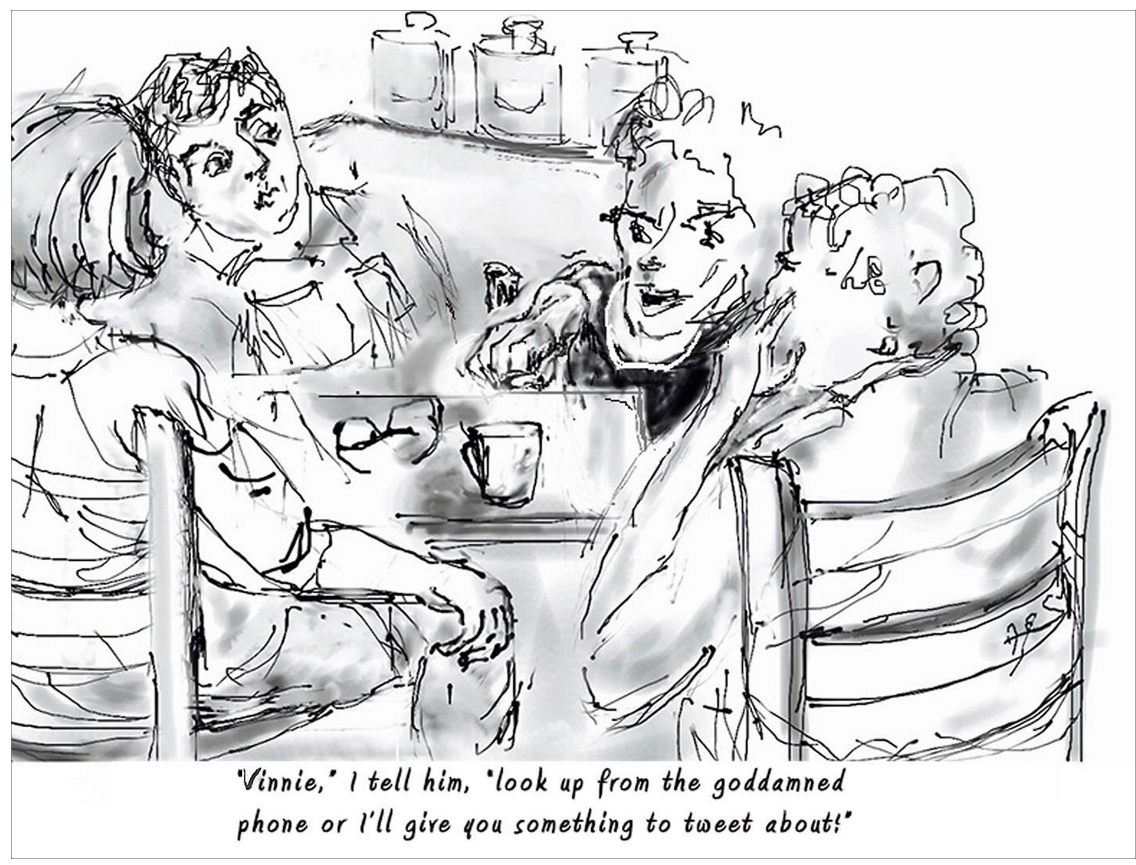

Figure 1. iPad drawing, scalable

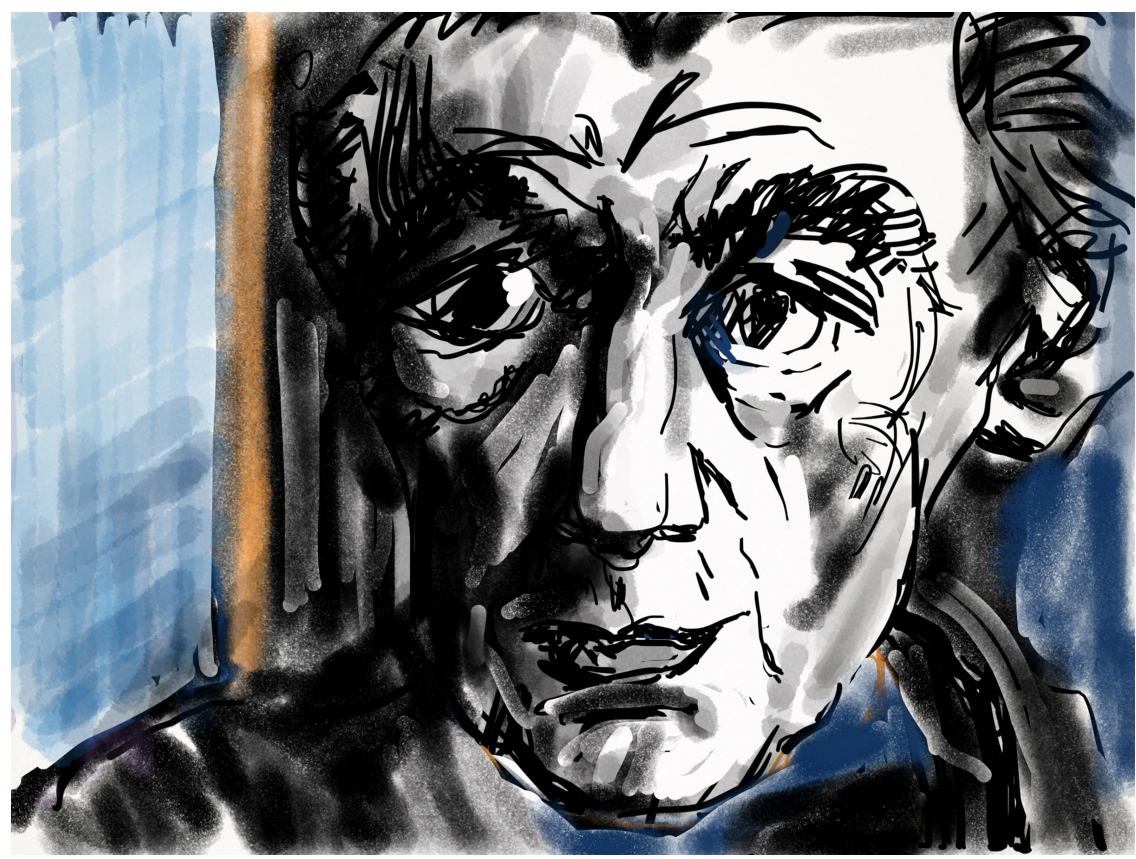

Figure 2. iPad painting, scalable

Art/Research International: A Transdisciplinary Journal/Volume 1, Issue 1 
In an online book review, following our initial conversation, I wrote:

I imagined JES [Schavrien's penname] seated at a side table in the cafés with her iPad, by now a device as ubiquitous as a cellphone or laptop. And although the artist presence in the café with a sketchbook (or doodling on napkins) is not a new phenomenon, there is something about drawing on the iPad that links this artist and her work with those around her in the café. She might be the object of their gaze and fantasy, as they are hers. (Netzer, 2015, September 14)

Schavrien's remarks about the Rabbithole Café as the incubator of and the inspiration for this body of work echoed my thoughts. In the preface to her book she wrote:

Alice had her mantra: "curiouser and curiouser" (Carroll, 1865/1981, p. 8). It kept her sane as she travelled through a wonderland. But even everyday-life morphs in a minute, opening suddenly into the weird, or the archetypal, or simply what moves the heart.

If a number of the characters converse more with their laptops or smartphones than with companions in the flesh, please take it as a sign of the times. Wasn't I too on the scene, cloaked in dark glasses so as not to scare the horses, marking a trusty iPad?

My years installed at a café, or in a psychotherapist's chair, play their role in how the characters \& their situations are rendered. Still, the readings, I hope, leave room. (Schavrien, 2014, p. 1)

Larger than life, whether in pastel, oil, or spray-paint on pleated screens suggesting street art on corrugated garage doors (Figure 3), Schavrien's paintings have always relied on nuanced affect, precise choices in her palette, and layered painterly gestures. Her relation to the media had been invariably experimental. Her paintings frequently left me wondering about the stories behind the faces, and her tendency to carefully select a title or caption for her artwork left me with further questions, e.g. should there be captions at all? They invited the construction of narrative by the viewer. The faces Schavrien paints are both particular and representative of a larger human concern, one that I wanted to understand more fully.

\section{Method}

As important as the subject of this interview is its methodology. The conversation and the reporting of it take a dialogic approach, with participatory elements. A dialogic approach to interviewing is probing in nature. It is not scripted, and as such challenges the interviewer and interviewee's assumptions, invites elaboration, and expands selfawareness on the parts of all who participate as equal members of the transformative 
exchange (Way, Zwier, \& Tracy, 2015). Given a constructivist paradigm in which "reality is socially, specifically, communicatively, constructed, it makes sense to treat interviews as opportunities for meaning making and transformation" (Way et. al, 2015, p. 271).

It has long been established that collaboration with participants and the inclusion of thick, rich descriptions of the inquiry's background, setting, and participants' accounts are paramount to the credibility and trustworthiness of qualitative research (e.g., Chenail, 1995; Creswell \& Miller, 2000). If the researcher only acts as reporter of meaning-units, thematically extracted from the interview, the audience is excluded from the interview's shared, co-constructed experience. Conversely, detailed accounts create verisimilitude, a life-like authenticity that is natural and, therefore, more resonant than a neutral report of facts (Creswell \& Miller, 2000); the researcher's openness to present, rather than only re-present the participants builds trust with readers (Chenail, 1995). Inviting the audience into the conversation seems to me particularly appropriate for the exploration of art-based inquiry. Just as researchers make an effort to reproduce images of artwork in their entirety, so does it make sense to maintain the verbal data in a form as complete, even organic, as possible.

I wanted to know more about Schavrien's creative process, and how she transitioned into the contemporary medium of digital painting. Engaging in this conversation-one between two colleagues, who continued to share a view of both research and art as catalysts for personal and social change-l invited Schavrien to expound on the undercurrents of her work. We recorded our conversation and, some time later, each examined the transcript and decided to prepare it for publication by continuing our correspondence. Our collaborative work with the transcript revealed not only insight into Schavrien's current artwork, sociopolitical activism, and contribution to the field of transpersonal psychology, but also demonstrated an interactive and mutually transformative exchange, which is one of the hallmarks of transpersonal approaches to qualitative inquiry (e.g., Anderson \& Braud, 2011).

We chose to present the interview in a holistic manner to encourage a participatory, co-creative, and potentially transformative experience for the reader as well. Our approach is grounded in a transpersonal theory (Ferrer, 2001, 2011) that identifies pluralistic, whole-person engagement in life events as spiritually sacred-a way of expanding spiritual knowing beyond pre-established concepts about spirituality, a singular dogma, or individual experiences that attempt to define Spirit. Ferrer conceives spirituality as co-enacted through unmediated, embodied connection with the sacred in everyday life, which is made possible through all who contribute to the happening of the unfolding mystery of life (Ferrer, 2011). In this article, the exposed dialogue reveals the dynamics that have co-birthed thoughts and felt responses about Schavrien's lived experience of art as transpersonal in socio-cultural and political terms. 
By keeping the data permeable, we invite the reader to join us, engage and interact with the conversation, and further expand its initial co-created meaning.

\section{The Interview}

In this interview Schavrien discusses the philosophical and ideological background for her current approach to art making and, by so doing, situates the café as a social context that is intrinsic to contemporary art's transcendence of traditional mediums, forms, and spaces. On the other hand, she continues to reference art history and the ongoing social dynamics, both of art content and its effects. Schavrien's perspective on life in a café is of an American Babyboomer. The work calls, however, not just to Boomers. In the café scenes, the generations intersect. When I asked her to articulate in a sentence what she does as an artist, she said: "I address the contemporary scene while reaching into the past" (Schavrien, personal communication, September 2, 2015). This response was reminiscent of Schavrien's approach to artsinformed transpersonal scholarship (e.g., Schavrien, 2010, 2013).

J.S: Both the art and the scholarship attempt to plumb depths of personality, even depths of soul. Transpersonal studies inquire into a person's relation to a larger whole. My scholarship (e.g., Schavrien, 2010, 2014) examines works from James Joyce's Finnegans Wake, to Shakespeare's late romances that include Cymbeline, The Winter's Tale, and The Tempest, to works by Sophocles such as Oedipus at Colonus and by Aeschylus, The Oresteia. It pursues a psychological analysis that spans both depths and heights along the consciousness continuum-collective unconscious on the one hand, myth and archetype, and, on the other hand, spiritual heights, mystical moments and visions. At the same time, it puts the authors and their work into cultural historical context. My art, like the scholarship, aims to make present to the viewer the people portrayed, and yet set them one way or another in the context of their times-whether through exploring in a café setting a contemporary phenomenon like tweeting (Figure 1) - or through setting the subject of a portrait in a contemporary psychological environment of existential angst (Figure 2) or a context of abstractions, such as horizontal pleats, that interrupt the face (Figure 3). To me the scholarly work and the artistic work are continuous, although they articulate through different languages, and deploy, as I create them, different faculties. Sophocles' Oedipus at Colonus and Shakespeare's The Tempest, each examined in my scholarly articles, spotlight not just characters on the brink of death but also a generation of innocents. These plays are, in fact, their own kind of research, enhancing knowledge of the transpersonal-probing into, through, and beyond the personality. Neither Shakespeare nor Sophocles stop there: They also explore the worst that the human and even the animal-in-the-human (Creon, Caliban) can attempt. I am in sympathy with that and aim to show personality ensconced 
in, emerging from, not just light but also shadow. ${ }^{3}$ The scholarship I do informs in these ways my art, and vice-versa.

D.N.: What, in your view, then, is the task of the artist?

J.S.: Let me respond by referring back to James Baldwin (1985), an early African American novelist, who maintained that the task of the artist is to go out on a limb and help free society from the corset of bourgeois convention. For an artist in tribal culture, at least in the old times, it would be different: She might be the custodian of the culture, carving and decorating, say, musical instruments or else shamanic tools, replicating to some extent the way they've been made for centuries with nevertheless variations and inspirations. At least this was Baldwin's view when he wrote from the '50s onward. The point about being instead an artist in a bourgeois society is that you attempt to break through, innovate, so that people don't suffocate, trapped in their middle class compulsions. An artist takes the risk of being marginal, out on a limb. Of course, you can do something different, art that's sure to sell, but that's not the art intended to push society forward.

D.N.: I hear you describing what I call 'art as a transpersonal practice,' though it may not be characterized this way by contemporary artists who are politically informed, and who similarly aim to challenge conventions as a way to spark social transformation.

\footnotetext{
${ }^{3}$ True transpersonal development is not possible without addressing the individual and collective shadow (Daniels, 2005). The shadow, a Jungian concept, refers to those, often negative, aspects of the psyche that are difficult to acknowledge, and which must be examined and made conscious in the process of developing personal and interpersonal awareness of the need for change. Schavrien often engages the shadow in her portraits, for example the shadows under the brow and in the deep eye sockets; how might the person and personality look different in those parts of the portrait from the look where high cheekbones, a fleshy underlip, a strong jaw caught the light? The latter might be strong, without secrets, while the mysteries in the eye-sockets were hanging back.
} 


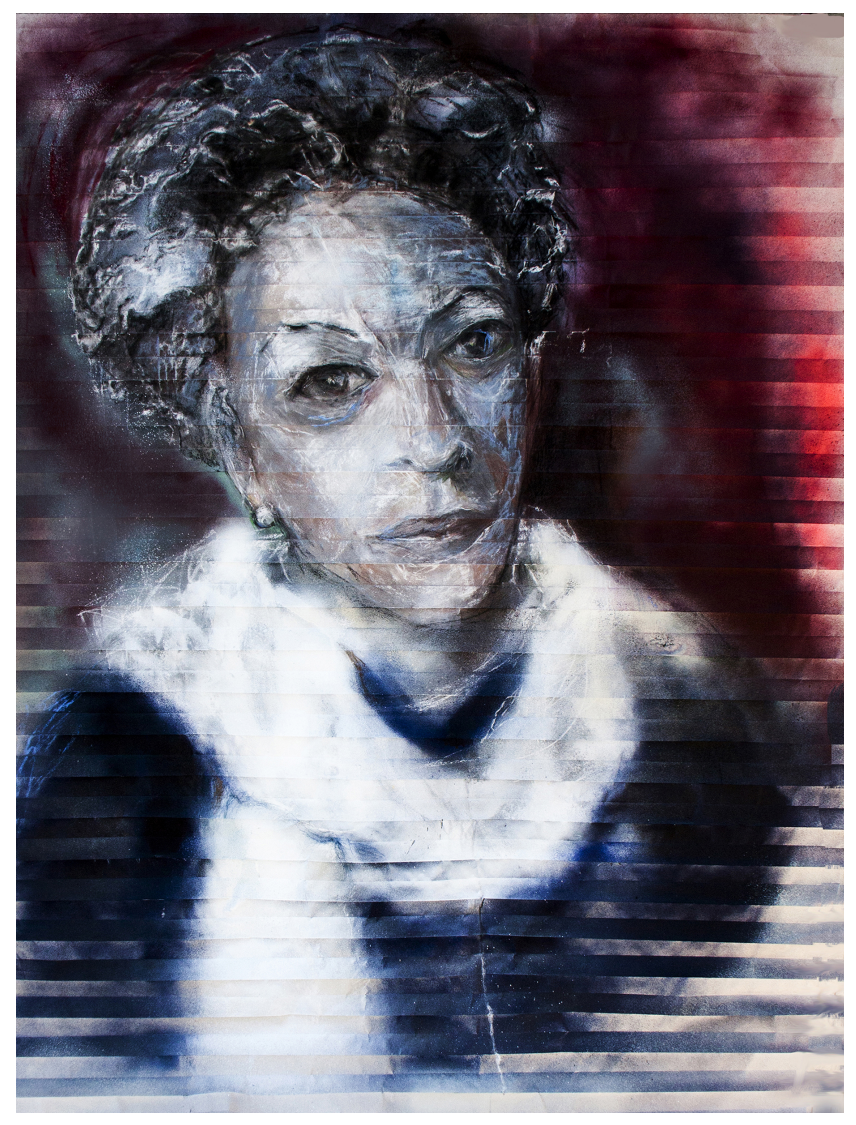

Figure 3. The Novelist, Arrived, spray-paint/pastel on paper pleated screen, 48 "w $\times 72 " h$

J.S.: Yes. After all, that's what you and I have in common-a dedication to both. The transpersonal on the one hand seems to answer to this prescription, seems out there on the margin. You exist not just personally but through and beyond the personal-mysticism, meditation, death and dying, creativity, the collective unconscious, the ecology of the planet, any one or all of these. But I could reverse the assertion that transpersonal researchers, therapists, artists are dealing with marginal concerns. Those of us who embrace the transpersonal consider not just the field, but the fact of transpersonal existence central to psychology, anything but marginal. Transpersonalists take the most inclusive approach; they concern themselves not just with the egocentric "l" but with the "l" relating to a larger whole. The more inclusive approach really is the truth about what is happening, whether people experience this consciously or not.

D.N.: It is interesting to hear how you situate yourself-a contemporary, female artist whose work relies on a transpersonal understanding of the psychology of the arts. 
J.S.: Yes, and of life.

D.N.: What is the psychological state of the contemporary artist-representing, perhaps, the voice that the middle class doesn't want to hear?

J.S.: Yes, exactly. Or wants to hear, but only on holidays.

D.N.: You're right [smiles].

J.S.: Or drunk—needing an escape valve from the daily pressures of conventional behavior. If I'm a good burgher, pressed by my obligations or my seemingly virtuous career ambitions, I open my escape valve now and then. I let off steam. Then I go back to the grind. I'm caught in the grind and feel relatively helpless to change the waves of history, that are just washing over; for instance, the largescale pillaging both of the planet and its populations in pursuit of obscene wealth (Cf. The People Cry Out!, Figure 4).

A figure like Basquiat ${ }^{4}$ called people's attention to street art and furthered its inclusion in high art. He began as a graffiti artist and became a Pop art darling. This harked back to the surreal and dada movements, which aimed to alert ordinary people, by way of art, to possibilities for psychological and social revolution-from the latrine signed by duchamp, to the lobster paraded by its owner, de Nerval, to Dali's melting clock. Basquiat became part of Andy Warhol's circle, which was engaged in relating the bourgeois to the artistic through films and other artworks, without, on the one hand, camouflaging the deadly boring aspects of daily bourgeois life, graced for example by rows of corporate soup cans, and without, on the other hand, abstaining from shock tactics that challenged bourgeois orderliness, property worship, gender definition, and so on.

D.N.: Can you say more about how you relate to this movement?

J.S.: If I am your average burgher, I can escape, for the moment, to "way out," but I don't do much more. Well, maybe I get some therapy, since something is bothering me, I'm not always sure what. Artists, however, live where the action is.

\footnotetext{
${ }^{4}$ Jean-Michel (1960-1988) began his short-lived career in 1978 with his rebellious street graffiti, but his authenticity attracted the attention of the mainstream art scene in New York. He continued to apply the same style to canvas, which was presented in museums and galleries worldwide. http://www.jean-michel-basquiat.com/
} 
They sometimes die there too. Capsize. In my '20s, it was the Boomer generation, the Vietnam war, the women's movement, the civil rights movement, mind drugs. When I really turned around and said, "Now I'm going to be a poet," I thought uh-oh, I can live to write and I bet I'll be addicted because I'm trying to live always in that altered state of mind. I was basically a good little girl who needed help to get into an altered state. I made a choice: I'm not going to live to write. I'm going to write and live-so that I'm still alive at 40 . There were art and music heroes of my generation like Jimmy Hendrix, Janis Joplin. They were pioneers of that generation and they died young. The poets, Sylvia Plath, Anne Sexton, Theodore Roethke-died before their time.

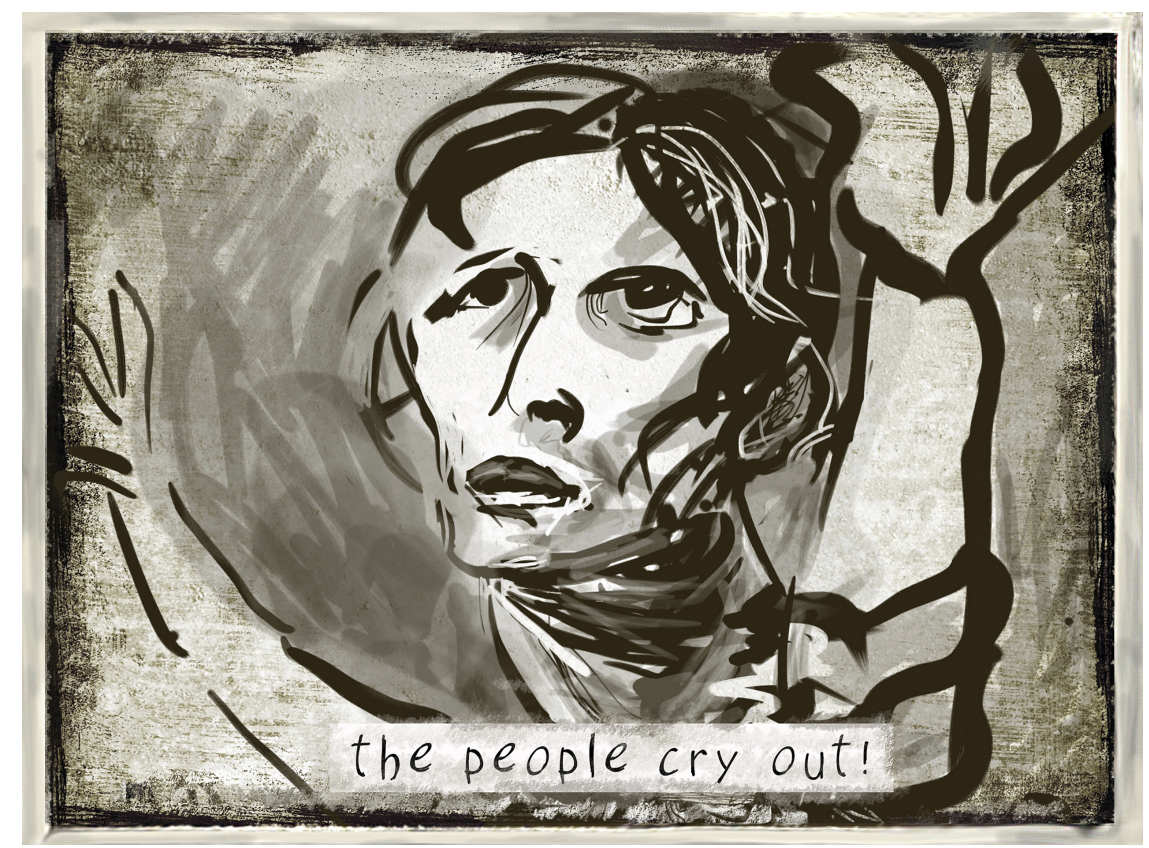

Figure 4. iPad print, scalable

D.N.: I wonder, though, whether freeing society from established conventions at the cost of relying on addictive substances might be a form of spiritual bypassing? I'm referring here to what, as you know, transpersonalists mean by this phrase: considering yourself on a plane higher than politics, meditating on the mountaintop, but you are really just in denial, reinforcing old defenses (Welwood, 2000). As to the artists who do their dangerous work by looking directly at the apocalyptic issues, but are, on the other hand, burning themselves out on drugs or on sheer anxiety-could it be that they lack the psychological grounding to be a change agent interconnected with a larger whole? Is there another, more inclusive way of "going out on a limb," as you put it, without becoming either trapped in the grind or instead falling into addictions, or some other, quicker form of self-destruction, interpreted as social activism? 
J.S.: Yes, not an ideal scenario- the confessional poets of that generation, Theodore Roethke, along with Plath and Sexton-suicides. So many of my generation died young, but at least they had made their mark. I was looking at them-being a poet myself at that time. American society was in such violent trouble, and a poet's job was to articulate this. To do so-not theoretically but instead from up close-well it was an invitation to stick a wet finger in a live socket.

D.N.: Did you begin your creative work as a scholar?

J.S.: Yes, I did. But I was engaged with the arts all along. Parallel tracks.

D.N.: Since you trained as a scholar, perhaps your intellect grounded you in a way that you were not only in the midst of social turmoil, but also observing it. You were talking about it or to it as a scholar.

J.S.: I should add that the scholarly approach might ground you but it can also endanger the creativity. At the University of Chicago, where I went to school, you were sharpening a rapier wit that could penetrate chinks and make your opponent look foolish. Mustn't have a chink. I guess you'll be made to look like a woman, eh? Academia really didn't have room for a woman's approach to knowing. Later, when a team of us founded the world's first two higher degrees in women's spirituality, Masters and doctoral, we explored women's ways of knowing. They were different.

As to traditional academic scholarship: true, it's a wonderful discipline, but it also threatens to keep you in your head, excluding what your body, your heart, your spirit knows. Of course not just feminist but also the holistic transpersonal approach can include these other knowings. That is why both the humanist and transpersonal communities should resist the "Prodigal Son" script of attempting a return to "chinkless" knowing. That's a big topic, but, in short, using math and math only to sidestep the iffy aspects of qualitative research (such as Heuristic Inquiry, meditative and artistic approaches, action research) would be a fatal mistake. The desire for certainty may trump the addressing of crucial human questions or it may cut those questions down to a size suitable for limited tools. If the latter is the case, if the mystery of, say, whether there is life after death risks distortion when investigated only by a likert scale, this should be clearly acknowledged in the research report itself. Both approaches together, qualitative and quantitative- that can work well; but not one excluding and even disdaining the other, not the quantitative disdaining the qualitative. 
D.N.: It's interesting to me, because in your current book of drawings and cartoons the academic and artistic "tracks" are no longer parallel. You are far from "chinkless," and you speak the language of contemporary culture-observe it, satirize itespecially when you disclose that these drawings were done on the iPad.

J.S.: Right, yes!

D.N.: You also include language, not academic or poetic, the language of contemporary cartoons or graphic novels, which is familiar to a much wider audience, and at the same time, as you said before, you still root the work in your scholarship. We've been talking about your psychology scholarship but I'm also thinking about your art scholarship. You just can't deny what you know.

J.S.: Right.

D.N.: You blend psychological observations and your traditional training as an artist, and all of that gets melded into the image, which is a commentary on society...

J.S.: I am grateful for what you see in my art. You look with such comprehending eyes. I have to admit, by the way, that walking through the world with the knowledge you accumulate as a psychotherapist, not just a researcher but a hands-on worker in the trenches-it's always a feast. You look at someone in a café, or coming toward you in the street. So many likely stories call out to you from the way they've grown their face, their body, or their gait... where they came from, where they're going.

D.N.: It seems, though, at least at first glance, that combining these two approaches, of the scholar and the artist, is somewhat self-contradicting. But maybe you are giving voice to something new? I see you making a mark in a new way, and I'm interested to know more about it. It seems very different from either, let's say, a New Yorker cartoon or the current graphic novel style or, on the other hand, a traditional lithography or other form of print making. You're planting yourself neither here nor there. Is the art teasing the bourgeoisie or speaking with its voice? What are you saying really with your method? I speak here, specifically, of your iPad café cartoons and the print-like portraits in your book Alice at the Rabbithole Café.

J.S.: There is undeniably reverence for the tradition, but the tradition is full of people who are breaking the tradition in their time. Daumier obviously was not going to be embraced by the French academy with his fierce satire on contemporary professionals and the government. In fact, he ended up in prison. The Expressionists, who distort form and color to convey emotion, the Austrian Expressionists and German Expressionists in the early 20th century, got thrown in prison, sometimes for being too sexual, ambi-sexual even, like Egon Schiele, or for being too outspoken about political currents. They portrayed Nazi faces when those faces were still new on the scene. Then Hitler condemned them as 
Degenerate Artists (e.g., Barron \& Guenther, 1991). Yes, I have deep reverence for the traditional greats, but they were often people who themselves were original enough to get themselves torpedoed or, at best, ignored by the establishment. Van Gogh is of course a prime example. Rembrandt did rise to the top, but then he fell out of fashion. As you suggest, I do some innovating by bringing the high tradition into what might be viewed as low art, cartoons and computer art. The latter still attracts the enmity of some in the art Establishment, by the way, but I say it is important to bridge the generations.

D.N.: Can you say more about that?

J.S.: It's the same thing that I'm doing when I spray-paint on large pleated shades (Figure 3). I put on my gas mask like the teenagers who go out and do graffiti, although sometimes they just protect themselves with bandanas. Yes, I was thinking of the street kids as I did what looks more like high art, but in their technique, in their mode.

Why was I thinking of them? Because l'd rather embrace what kids are doing to have a voice than see them out on the streets mugging people. I'm certainly sorry that graffiti hurts property owners. Yet those same kids could've been in the gang that shot me in a mugging in Chicago. ${ }^{5}$ l'd rather they had spray-paint in their hands than a gun. I sympathize with the facelessness that this society assigns to them. If they want to de-face, I understand.

D.N.: I would say understanding is probably what you're doing and, for me, understanding is probably the first transpersonal quality that comes to mind. It's appreciating differences, understanding rather than judging.

J.S.: Yes, I agree.

D.N.: Compassion.

J.S.: Feeling with, feeling with. When I was spray-painting that series of large pleated shades, I was trying to make my way into graffiti, as if the shades were a wall. (They're on display now in San Francisco, in a café in the Mission neighborhood, so famous for its mural and graffiti walls). I found that I couldn't write graffiti the way the street kids can, just could never get it to come out right. I was thinking

\footnotetext{
${ }^{5}$ For the account of this mugging in which she was shot in the face, see Schavrien's article "On being shot awake and the dreams that foresaw it: A transpersonal self psychology view of PTSD recovery," Journal of Transpersonal Studies 37(2), 99-123. http://www.atpweb.org/jtparchive/trps-37-02-099.pdf
} 
words, words, words, but they were not happening on these screens. I finally found my way to words, but instead they happened in the iPad cartoons and portraits.

Yes, I do want to bridge to the other generations. When I gave a presentation of the iPad drawings and I said, "They are a Boomer sensibility," and someone in the audience commented, "Maybe that restricts you to a narrower audience." One of the young guys said, "No it doesn't. You can do computers. That's great."

\section{D.N.: Makes sense.}

J.S.: It's okay to both keep up with what's happening and bring the past into it. I don't make a deliberate attempt to do something different. Then l'd be falling in with what the New Yorker critic, Harold Rosenberg, called the tradition of the new. I don't worry about that because if you do it from yourself-if you bring into the work your feelings and your thoughts, what you care about and the way your hand moves-the work will be from the origin. That's original.

D.N.: Right.

J.S.: You can do something to call attention to yourself and to be clever and witty and unusual, but if you really want to be original, just take it from the origin. That's what I mean. I don't mind people having a gimmick or pulling off a prank and calling it the next movement in art, but as far as I'm concerned, it's a little too easy.

D.N.: Yes. Perhaps their aim is different, perhaps it is sensational rather than ...

J.S.: You know I sometimes wish I had that kind of ego. Painting the big screens, trying to do that graffiti signature, making it as large and self-announcing as possible, I gave up. "Oh, no, this is a young guy's ego. I can't manage it."

D.N.: Too late for that... [smiles]

J.S.: Too late.

D.N.: Can we return to the computer art process? A traditional artist might have to discard a work in which the changes seemed to spoil it. But is yours more like a Photoshop process, allowing you to change your mind and reconsider?

J.S.: I do best when the reconsidering is done while I'm sketching, every other second. Do, undo, do, undo ...

D.N.: Part of the process. 
J.S.: Jim Dine (1980), for example, erases half the face. He'll do a face and then (or as he goes along) he will erase half of it. It's partly because we all as contemporary people have interrupted lives. When you look at one of my big screens (Figure 3 ), for instance, there are pleats interrupting the face, as my face got interrupted by a gunshot in a mugging. That was in Chicago. That was a bad night. On the other hand, interruption is just a contemporary theme, quite typical. We all have constantly interrupted lives and even interrupted personalities...You do your best to start over again.

...In my own work I aim for a certain instantaneity. You can view this as the New Physicists' ongoing Process or as Buddhist impermanence. ${ }^{6}$ I try to capture the spark of life, as if someone had just moved or is just about to move; as if light or shadow could overtake the person, because she exists in a constantly changing environment. If you look at a work of mine called The Jewish Actor (Figure 5), you'll see, once again, what the computer can offer. The piece is one I did in wet and dry pastel. It began, however, with a freeze-frame I did on the computer while viewing a video of the actor, Erland Josephson. A technique like that can highlight the instant. But there is an additional challenge: How can I bring the viewer under the skin? There are layers. Blood flowing in capillaries, impulses in nerves, a kind of layered, moving reality. This layering aims also to suggest the layers of the personality. All of this is an outgrowth, at least in the case of my own art, not of the computer but of the artist's hand, moving. Finally, along with the movement there is an essence I hope to catch. The Tibetan view the eyes as the window to the soul. Luckily, eyes I can do. ${ }^{7}$

\footnotetext{
${ }^{6}$ Transpersonal psychology includes the study of underpinnings that are variants, complications of, even contradictions to nineteenth century materialist assumptions (see for example, Fritjof Capra, Tao of Physics).

${ }^{7}$ A detailed discussion of Schavrien's approach to this portrait was published in the International Journal of Transpersonal Studies special section on Arts and Consciousness, 2015.
} 


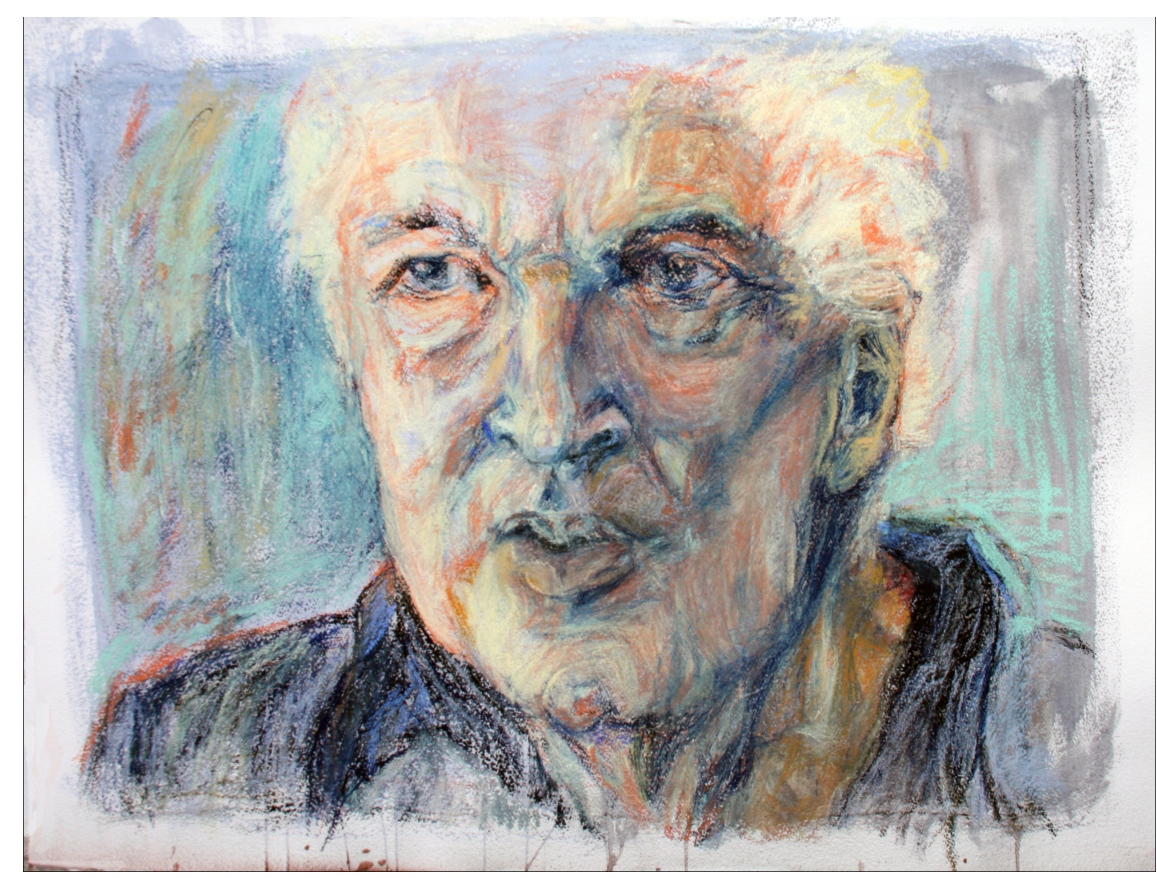

Figure 5. The Jewish Actor: Erland Josephson, wet/dry pastel on archival paper, 28"w x $22 " h$

D.N.: Would you say that at any point your portraits of others act as self-portraits?

J.S.: $\quad$ Oh, yeah, there's a lot of me in it. It may be why The Novelist, Arrived (Figure 3) turned into someone half black and half Jewish. I don't have that particular Jewish jaw, but still I have the east European Jewish background.

D.N.: Is that another way in which the portrait taps into your origin?

J.S.: Right, right. My origin, that's right, that maybe I have experienced some of what they've experienced; but they're also different from me. The late Josephson (Figure 5), whose insides I portray, was more accomplished as a mover and shaker than I. He was head of the Swedish Royal Dramatic Theatre. Likewise the novelist might be more "arrived" than I am, socially or spiritually. (One of my inspirations for her was the Nobel Prize winner Toni Morrison). Still, I can perceive the accomplishments of both, the level of development. I may not be capable of living as they do but at least I can appreciate them. After all, l've portrayed Christ on the cross, but I have no pretensions to...

D.N.: What l'm noticing is that similar qualities appear, whether your object is a model in the studio, a stranger in a café, or a particular artist, writer or filmmaker. With your models, you are choosing very carefully, including choosing which frame to freeze with great intentionality. Can you choose with the same intentionality in the café setting? 
J.S.: In the café the people are setting the terms, but I can look 360 around the café and say, "Now there's an interesting face." I can do that, but it's very hard when I'm doing three or four people at once. I'm just scrambling to keep up and I'm lucky if something emerges.

D.N.: Are you listening to the conversations as you sketch? Do your captions emerge from the conversations you hear, or do you project your own thoughts after looking at your drawing?

J.S.: Both. Sometimes the captions emerge out of the script in the café, and sometimes they come to me in a hypnogogic state, first thing in the morning. I wake up laughing.

D.N.: I'm curious about the way you have paired captions with images in your iPad book. Should the images perhaps just speak for themselves, as your pastel portraits do?

J.S.: I was a purist for a long time. I thought I really shouldn't influence the pure visual experience people have when they look at my work, but I'm at a point where I just want to use everything l've got. I like words. I like images. You don't have to think what I think, but I'll tell you what I think.

D.N.: This shift in thinking must open you to all sorts of new mediums.

J.S.: Right.

D.N.: And in terms of your subject matter, are you seeing yourself staying with portraits?

J.S.: I began producing the cartoons and colored prints of this iPad book at a time when I dearly needed healing. My healing practice substituted for the experience of being an online teacher, which kept me in a fairly monastic mode, at the computer several hours a day, interacting with students. It was wonderful to interact with wonderful students. Global to interact with global, online students and yet, there was a monastic dimension. As the academic politics in the school got worse and worse, there was the ongoing misery, for me and many of the faculty, of being caught between a rock and a hard place-defending our students and our own integrity meant risking our jobs. To heal from that, when I was set free into retirement, I was out every morning at the café and, since I am organizationally challenged, I was thrilled to need only my stylus and my iPad. That was so much better somehow than having to find a sketch book and paints. 
D.N.: And the iPad must have attracted far less attention.

J.S.: Attracted less attention because everybody's there with their computer or their smart phone, except for people of older generations. There was something so healing about being out and about all the time, wonderful opening therefore to four to five people interacting. It was no longer pure psychology or pure spiritual or existential portrait. It was now sociology, social psychology, seeing what was happening out there. Of course, there were the graphic challenges of producing people interrelating, and four or five around a table. Hands, I did a lot more hands than usual, could catch a hand in flight. But l'd sometimes discover, when the people pushed away from the table, that I had drawn a torso sprouting from the table. Strange centerpiece...

D.N.: There is such an immediacy and directness in your drawing. Time is of the essence. The lived experience changes constantly.

J.S.: Right, but I have to tell you, people caught me at it. You can escape getting caught, at least escape it better, if you put your dark glasses on. People were fascinated. They just loved it.

D.N.: Interesting.

J.S.: It's something I can send to them in the email, whereas you'd be loath to part from your only lonely sketch of them.

D.N.: Yeah, yeah, so it becomes almost like a collective experience.

J.S.: It's catching, it's catching, and they were people often of the older generation, who had been Sunday artists and who now had time to take the art more seriously. They just couldn't believe I was doing that on the iPad.

D.N.: And yet you keep going back to the messiness of traditional art materials.

J.S.: I do. Have to. It's what keeps me experimental, what keeps it always new.

D.N.: We could go on and on, but I feel your last statements brought us full circle to your earlier comments about reaching into the past with commentary about the present, as well as tapping into contemporary society as a way of healing the past. I also think it may be carried as an analogy to your view of transpersonal scholarship and research, and the importance of resisting the "desire for certainty" as you said. In your current art making you continue to risk not knowing, continue to be experimental with your iPad, and at the same time you return to the messiness of your large-scale portraits, where you get to know the human face through your whole body. This seems to guard against the desirefor-certainty's reductionist threat, to invite multiple ways of knowing, to persist 
asking those crucial human questions, and to offer an investigation that keeps the conversation going.

J.S. I'll add one more thing. Not only does the art, especially when I'm doing it in the café, draw people to me, but l'd say, when I succeed, that all forms of my art invite a kind of participation. To "get" the piece, the viewer must fill it in with a kind of empathy. The art work is completed inside the viewer. There is a parallel with my research. I give biographies of Shakespeare and Sophocles and descriptions of their times as a necessary context for exploring their transpersonal themes. This too provides a participatory element for any reader. A reader, or a viewer, I want to bring them close and invite them inside what is happening. The work completes itself in the audience.

\section{Conclusion}

My conversation with Judy Schavrien prodded me to fundamentally reconsider things I took for granted, and keep open the various definitions of art forms, activism, and scholarship. In that, she remains a transpersonal teacher, as she teaches what she practices. Schavrien's art spans wide in subject matter, medium, and scale, ${ }^{8}$ from the public, humorist commentary of her iPad café sketches, to political commentary pieces such as The People Cry Out, to richly colored expressive commentary, stroke by nuanced stroke, in her intimate portraits.

Schavrien's scholarship not only focuses on the analysis of arts (e.g., both Shakespeare and Sophocles are thinking in images that get fleshed out on the stage), but she also communicates thought through image rather than through concept alone. For a transpersonal scholar, imagery does a uniquely excellent job of conveying a holistic experience, which is a central tenet of transpersonal studies. The image speaks the language of the heart, activates all the senses, carries emotions, and, sometimes, whatever animates the whole being, which one might call "spirit," as Schavrien said about her portraits: "If there is soul in the eyes of my people, I have succeeded." Schavrien's training as a transpersonal psychologist deepened her scholarship and artwork. In her portraits and writing, she has been able to expose existential crises and examine them in the context of a potentially transformative, greater whole that encompasses and transcends human nature by not denying personal shadow and by remaining committed to social change.

In this article, a dialogic approach guided the choice to include the interview transcript alongside the art that inspired it, to expose large, organic wholes rather than

\footnotetext{
${ }^{8}$ You may look up other art works and articles by Judy Schavrien on www.jesart.net.
} 
re-present selective units of meaning. This participatory method aimed to extend the interview's reach, emotional as well as intellectual, beyond the limits of the source encounter between the artist and me, to honor the reader as a co-creative partner in the realization of this shared encounter. I invite artists and scholars, especially art-based researchers, to engage in this open-ended conversation about the role of art as a transpersonal medium of expression that challenges conventions, cries out, provokes thought, engages multiple ways of knowing, and offers alternatives that push society forward. 


\section{References}

Anderson, R., \& Braud, W. (2011). Transforming self and others through research: Transpersonal research methods and skills for the human sciences and humanities. Albany, NY: State University of New York Press.

Barron, S., \& Guenther, P. W. (1991). Degenerate art: The fate of the avant-garde in Nazi Germany. Los Angeles, CA: Los Angeles County Museum of Art.

Baldwin, J. (1985). The price of the ticket: Collected nonfiction. New York, NY: St. Martin Press.

Caplan, M., Hartelius, G., \& Rardin, M. A. (2003). Contemporary viewpoints on transpersonal psychology. Journal of Transpersonal Psychology, 35(2), 143-162.

Capra, F. (1999). Tao of physics: An exploration of the parallels between modern physics and Eastern mysticism. Boston, MA: Shambhala.

Carroll, L. (1981). Alice's adventures in wonderland. New York, NY: Random House. Original work published 1865.

Chenail, R. J. (1995). Presenting qualitative data. The Qualitative Report 2(3) [Online]. Retrieved from: http://www.nova.edu/ssss/QR/QR2-3/presenting.html

Creswell, J. W., \& Miller, D. L. (2000). Determining validity in qualitative inquiry. Theory into Practice 39(3), 124-130.

Daniels, M. (2005). Shadow, self, spirit: Essays in transpersonal psychology. Charlottesville, VA: Imprint Academic.

Ferrer, J. N. (2001). Toward a participatory vision of human spirituality. ReVision: A Journal of Consciousness and Transformation, 24(2), 15-26.

Ferrer, J. N. (2011). Participatory spirituality and transpersonal theory: A ten-year retrospective. Journal of Transpersonal Psychology, 43(1), 1-34.

Friedman, H. L., \& Hartelius, G. (Eds.). (2013). The Wiley-Blackwell handbook of transpersonal psychology. West Sussex, UK: John Wiley \& Sons.

Glenn, C. W. (1980). Jim Dine: Figure drawings. New York, NY: Harper \& Row. 
Maslow, A. (1962). Toward a psychology of being. Princeton, NJ: Van Nostrand.

Maslow, A. (1971). The farther reaches of human nature. New York, NY: Viking.

Netzer, D. (2015, September 14). [Review of the book Alice at the rabbithole café: iPad art by JES Schavrien, by J. Schavrien]. ITP Alliance [Online]. Retrieved from: http://www.itpalliance.org/news--events

Schavrien, J. (2005). On being shot awake and the dreams that foresaw it: A transpersonal self psychology view of PTSD recovery. Journal of Transpersonal Psychology, 37(2), 99-123. Retrieved from: http://www.atpweb.org/jtparchive/trps-37-02-099.pdf

Schavrien, J. (2010). War and nature in classical Athens and today: Demoting and restoring the underground goddesses. International Journal of Transpersonal Studies, 29(2), 153-179. Retrieved from: http://www.transpersonalstudies.org//magesRepository/ijts/Downloads/Schavrien Erinyes corrected.pdf

Schavrien, J. (2013). Shakespeare's Cymbeline and the mystical particular: Redemption, then and now, for a disassembled world. International Journal of Transpersonal Studies, 32(2), 122-140. Retrieved from: http://transpersonalstudies.org/ImagesRepository/ijts/Downloads/Schavrien Shakespeare's Cymbeline and the mystical particular IJTS 32-2.pdf

Schavrien, J. (2014). Everything voluptuous: The love songs 1970-2014. Walnut Creek, CA: Blue Tile Press.

Schavrien, J. (2015). Alice at the rabbithole café: iPad art by JES Schavrien. North Charleston, SC: CreateSpace Independent Publishing Platform.

Schavrien, J. (2015). Transpersonal art-Does it bite? International Journal of Transpersonal Studies, 34(1-2), 211-214.

Way, A., Zwier, R. K., \& Tracy, S. J. (2015). Dialogic interviewing and flickers of transformation: An examination and delineation of interactional strategies that promote participants self-reflexivity. Qualitative Inquiry, 21(8), 720-731. DOI: $10.1177 / 1077800414566686$

Welwood, J. (2000). Toward a psychology of awakening: Buddhism, psychotherapy, and the path of personal and spiritual transformation. Boston, MA: Shambhala. 